Virna Museliza, Afrizal, Risma Elizal Pengaruh Program Keluarga Harapan (PKH) terhadap Kesejahteraan Keluarga Penerima Manfaat di Kecamatan Tampan Kota Pekanbaru

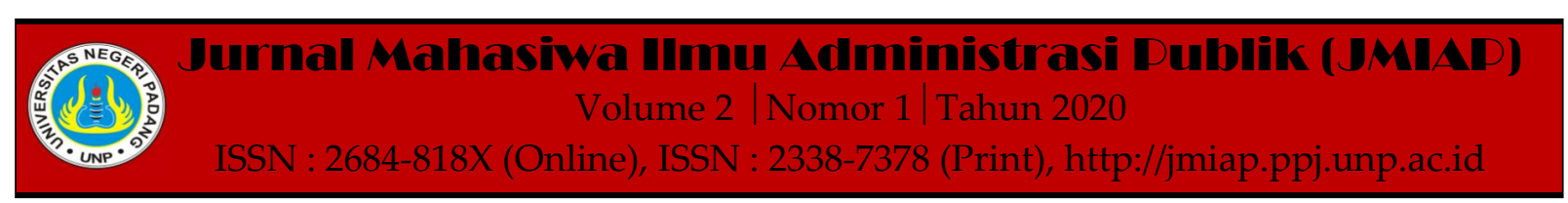

\title{
PENGARUH PROGRAM KELUARGA HARAPAN (PKH) TERHADAP KESEJAHTERAAN KELUARGA PENERIMA MANFAAT DI KECAMATAN TAMPAN KOTA PEKANBARU
}

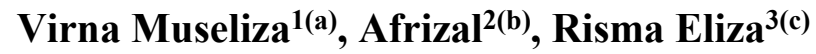 \\ ${ }^{1}$ Jurusan Ilmu Administrasi Negara, Universitas Islam Negeri Sutan Syarif Kasim Riau \\ ${ }^{2}$ Jurusan Ilmu Administrasi Negara, Universitas Islam Negeri Sutan Syarif Kasim Riau \\ ${ }^{3}$ Jurusan Ilmu Administrasi Negara, Universitas Islam Negeri Sutan Syarif Kasim Riau \\ a)vmuseliza66@gmail.com, ${ }^{b}$ ijalnoer69@gmail.com
}

\begin{abstract}
This research was conducted on the members of the Family Hope Program (PKM) in the Tampan sub-district of Pekanbaru City, the purpose of this study was to find out whether the Family Hope Program (PKH) affected the welfare of the Mafaat Beneficiary Family (KPM) in Tampan District, Pekanbaru City. The method used in this study is a quantitative method applied to 95 samples used as respondents using the Slovin technique, Likert scale. The results of the study concluded that the $R$ square of 0.345 means that the percentage of the influence of the Family Hope Program (PKH) on welfare is $34.5 \%$ while the remaining $65.5 \%$ is influenced by other variables not included in the regression model. In the regression equation $Y=9,888+0,487 x$. Where the $P K H$ variable $(X)$ has a positive and significant effect on the welfare variable (Y). Hypothesis testing obtained t count of 6,200. From the $t$ hypothesis test, the initial hypothesis of the researcher is answered, that is if t arithmetic $>$ from $t$ table $(6,200>1,986)$ then the conclusion of this study is the influence of the Family Hope Program (PKH) on the welfare of Beneficiaries (KPM) in the Tampan sub-district of Pekanbaru city.
\end{abstract}

Keywords : Family Hope Program (PKH), Influence, Welfare

Corresponding author. Email.vmuseliza66@gmail.com,ijalnoer69@gmail.com,

How to cite this article. Museliza, V., Afrizal., \& Eliza, R. (2020). Pengaruh Program Keluarga Harapan $(\mathrm{PKH})$ terhadap Kesejahteraan Keluarga Penerima Manfaat di Kecamatan Tampan Kota Pekanbaru. Jurnal Mahasiwa Ilmu Administrasi Publik (JMIAP) Jurusan Ilmu Administrasi Negara Fakultas Ilmu Sosial Universitas Negeri Padang, Volume 2 (1), Hal. 118-127.

http://jmiap.ppj.unp.ac.id

ISSN : 2684-818X (Online), ISSN : 2338-7378 (Print)

Copyright $\bigcirc 2020$. Published by Pusat Kajian-Pemberdayaan dan Pelayanan Masyarakat (PK-P2M) FIS UNP Padang 
Virna Museliza, Afrizal, Risma Elizal Pengaruh Program Keluarga Harapan (PKH) terhadap Kesejahteraan Keluarga Penerima Manfaat di Kecamatan Tampan Kota Pekanbaru

PENDAHULUAN

Kemiskinan masih menjadi salah satu masalah serius yang dihadapi oleh negara Indonesia, kemiskinan biasanya sangat sulit untuk diatasi terutama pada negara-negara yang masih berkembang, Indonesia sendiri merupakan negara berkembang dan masih mempunyai banyak masalah-masalah atau persoalan-persoalan yang dihadapi dan harus diatasi salah satunya adalah masalah kemiskinan. Kemiskinan merupakan masalah multidimensi yang ditandai oleh rendahnya rata-rata kualitas hidup penduduk, pendidikan, kesehatan, gizi anak-anak, dan sumber air minum.

Tabel 1. Basis Data Terpadu (BDT) Kemiskinan Di Kecamatan Tampan

\begin{tabular}{cccc}
\hline Kecamatan & \multicolumn{3}{c}{ Tahun } \\
\cline { 2 - 4 } & $\mathbf{2 0 1 6}$ & $\mathbf{2 0 1 7}$ & $\mathbf{2 0 1 8}$ \\
\hline Tampan & 29.030 & 29.030 & 28.229
\end{tabular}

\section{Sumber: Data Dinas Sosial}

Dari data pada tabel 1. dapat dijelaskan bahwa angka kemiskinan pada tahun 2016 ke 2017 tidak mengalami perubahan yaitu sebesar 29.030 ribu orang, namun pada tahun 2018 ini adanya penurunan angka kemiskinan di Kecamatan Tampan Kota Pekanbaru yaitu sebesar 28,229 ribu orang.
PKH merupakan bantuan dan perlindungan sosial yang termasuk dalam kluster pertama (1). Program ini merupakan bantuan tunai bersyarat yang berkaitan dengan persyaratan $\backslash$ komponen yang telah ditetapkan, persyaratan atau komponen tersebut sebagai berikut :

Tabel 2. Program Keluarga Harapan

\begin{tabular}{|c|c|c|}
\hline \multicolumn{3}{|c|}{ PROGRAM KELUARGA HARAPAN } \\
\hline & Persyaratan / Komponen & Kriteria \\
\hline 1. & Pendidikan & $\begin{array}{l}\text { Anak yang berusia } 6-21 \text { tahun dan terdaftar pada } \\
\text { satuan pendidikan dan belum menyelesaikan wajib } \\
\text { belajar } 12 \text { tahun }\end{array}$ \\
\hline 2. & Kesehatan & Anak usia 0-6 tahun, ibu hamil dan ibu nifas \\
\hline 3. & Kesejahteraan sosial & $\begin{array}{l}\text { Lanjut usia mulai dari } 60 \text { tahun dan penyandang } \\
\text { disabilitas diutamakn disabilitas berat }\end{array}$ \\
\hline
\end{tabular}

Sumber: PERMENSOS No 1 (2018)

Program PKH pada tabel 1.2 ini merupakan bantuan bersyarat yang mana persyaratan/ komponenya secara umum di bidang pendidikan dan kesehatan. Tujuan program ini adalah untuk mengurangi angka kemiskinan dan memutus rantai kemiskinan, meningkatkan kualitas SDM, serta merubah prilaku KPM PKH Yang relatif kurang mendukung peningkatan kesejahteraan. Tujuan tersebut sekaligus sebagai upaya mempercepat pencapaian target Millenium Development Goals (MDGs), ada 5 komponen tujuan MDGs yang didukung melalui Program keluarga harapan $(\mathrm{PKH})$ yaitu (1). Penanggulangan kemiskinan dan kelaparan; (2). Pencapaian pendidikan dasar; (3).Kesetaraan gender dan pemberdayaan perempuan; (4). Pengurangan angka kematian anak; (5). Meningkatkan kesehatan ibu.

Program keluarga harapan (PKH) diharapkan dapat mengurangi beban pengeluaran keluarga miskin dalam jangka pendek serta memutuskan rantai kemiskinan dalam jangka panjang. sebab peningkatan kualitas kesehatan, pendidikan, dan terpeliharanya taraf hidup masyarakat akan memberi kesempatan 
Virna Museliza, Afrizal, Risma Elizal Pengaruh Program Keluarga Harapan (PKH) terhadap Kesejahteraan Keluarga Penerima Manfaat di Kecamatan Tampan Kota Pekanbaru

kepada masyarakat untuk mampu

meningkatkan kualitas hidupnya.

Jumlah keluarga penerima manfaat di Kecamatan Tampan Kota Pekanbaru sebagai berikut:

Tabel 3. Data Keluarga Penerima Manfaat (KPM) PKH Di Kecamatan Tampan

\begin{tabular}{cccccc}
\hline \multirow{2}{*}{ Tahun } & Kelurahan & \multicolumn{4}{c}{ Tahap } \\
\cline { 3 - 5 } & & $\mathbf{1}$ & $\mathbf{2}$ & $\mathbf{3}$ & $\mathbf{4}$ \\
\hline \multirow{3}{*}{2016} & Delima & 28 & 28 & 28 & 28 \\
& Sidomulyo Barat & 43 & 43 & 43 & 43 \\
& Simpang Baru & 35 & 36 & 36 & 36 \\
& Tuah Karya & 63 & 63 & 63 & 63 \\
\multirow{2}{*}{2017} & Jumlah & $\mathbf{1 6 9}$ & $\mathbf{1 7 0}$ & $\mathbf{1 7 0}$ & $\mathbf{1 7 0}$ \\
& Delima & 142 & 142 & 141 & 141 \\
& Sidomulyo Barat & 289 & 289 & 288 & 283 \\
& Simpang Baru & 250 & 246 & 247 & 243 \\
& Tuah Karya & 439 & 441 & 441 & 439 \\
& Jumlah & $\mathbf{1 1 2 0}$ & $\mathbf{1 1 1 8}$ & $\mathbf{1 1 1 7}$ & $\mathbf{1 1 0 6}$ \\
& De18 & 248 & 247 & 246 & 244 \\
& Sidomulyo Barat & 511 & 507 & 506 & 502 \\
& Simpang Baru & 422 & 422 & 422 & 421 \\
& Tuah Karya & 811 & 811 & 793 & 788 \\
& Jumlah & $\mathbf{1 9 9 2}$ & $\mathbf{1 9 8 7}$ & $\mathbf{1 9 6 7}$ & $\mathbf{1 9 5 5}$ \\
\hline
\end{tabular}

Sumber: Data UUPKH Kota Pekanbaru

Berdasarkan data pada tabel 1.3 dapat dipaparkan bahwa KPM PKH di kecamatan tampan tahun 2016 KPM PKH tidak mengalami pengurangan namun di tahun selanjutnya tahun 2017 dan 2018 KPM PKH mengalami pengurangan jumlah KPM PKH.

Dengan adanya bantuan sosial berupa program-program pemerintah yang salah satunya adalah program keluarga harapan $(\mathrm{PKH})$ dapat menurunkan angka kemiskinan yang terjadi di Indonesia, dengan menurunnya angka kemiskinan di indonesia maka adanya peningkatan kesejahteran keluarga kurang mampu/miskin di indonesia.

Berdasarkan permasalahan tersebut maka penulis tertarik untuk melakukan penelitian dengan judul "Pengaruh Program Keluarga Harapan (PKH) Terhadap Kesejahteraan Keluarga Penerima Manfaat (KPM) Di Kecamatan Tampan Kota Pekanbaru”. Untuk mengetahui apakah Program Keluarga Harapan (PKH) berpengaruh terhadap kesejahteraan Keluarga Penerima Manfaat (KPM) di kecamatan Tampan Kota Pekabaru.

\section{TINJAUAN PUSTAKA}

Kemiskinan menurut PKH sama dengan kemiskinan menurut kementrian sosial (KEMNSOS) bahwa masyarakat dikatakan miskin jika memliki kriteria yang ditetapkan oleh KEMENSOS dalam keputusan Menteri Sosial Republik Indonesia No 146/HUK/2013 yaitu sebagai berikut:

1. Tidak mempunyai sumber mata pencaharian dan/atau mempunyai sumber mata pencaharian tetapi tidak mempunyai kemampuan untuk memenuhi kebutuhan dasarMempunyai pengeluaran sebagian besar digunakan untuk 
Virna Museliza, Afrizal, Risma Elizal Pengaruh Program Keluarga Harapan (PKH) terhadap Kesejahteraan Keluarga Penerima Manfaat di Kecamatan Tampan Kota Pekanbaru

memenuhi konsumsi makanan pokok dengan sangat sederhana;

2. Tidak mampu atau mengalami kesulitan untuk berobat ke tenaga medis, kecuali puskesmas atau yang disubsidikan pemerintah;

3. Tidak mampu membeli pakaian satu kali dalam setahun untuk setiap anggota rumah tangga;

4. Mempunyai kemampuan hanya menyekolahkan anaknya sampai jenjang pendidikan sekolah lanjutan tingkat pertama;

5. Mempunyai dinding rumah terbuat dari bambu/kayu/tembok dengan kondisi tidak baik/kualitas rendah, termasuk tembok yang sudah usang/berlumut/tembok tidak diplester;

6. Kondisi lantai terbuat dari tanah/kayu/semen/kramik dengan kondisi tidak baik/kualitas rendah;

7. Atap terbuat dari ijik/rumbia/genteng/seng/asbes degan kondisi tidak baik/kualitas rendah;

8. Mempunyai penerangan bangunan tempat tingal bukan dari listrik/listrik tanpa meteran;

9. Luas lantai rumah kecil kurang dari $8 \mathrm{~m}^{2}$ /orang;

10. Mempunyai sumber air minum berasal dari sumur atau mata air tak terlindung/air sungai/air hujan dll.

\section{Program Keluarga Harapan (PKH)}

Menurut Peraturan Menteri no 1 tahun 2018 program keluarga harapan $(\mathrm{PKH})$ adalah program pemberian bantuan sosial bersyarat kepada keluarga dan/atau seseorang miskin dan rentan yang terdaftar dalam data terpadu program penanganan fakir miskin, diolah oleh pusat data dan informasi kesejahteraan sosial dan ditetapkan sebagai keluarga penerima manfaat $\mathrm{PKH}$

Tujuan PKH menurut PERMENSOS No 1 tahun 2018 yaitu:

1. Untuk meningkatkan taraf hidup keluarga penerima Manfaat melalui akses layanan pendidikan, kesehatan, dan kesejahteraan social;
2. Mengurangi beban pengeluaran dan peningkatan pendapatan keluarga mislin dan rentan;

3. Menciptakan perubahan prilaku dan kemandirian keluarga penerima manfaat dalam mengakses layanan kesehatan da pendidikan serta keejahteraan social;

4. Mengurangi kemiskina dan kesenjangan.

\section{Pandangan Islam}

PKH merupakan salah satu program untuk mengentas kemiskinan, islam menganggap kemiskinan sebagai suatu msalah yang memerlukan penyelesaiaan. ALLAH telah menyinggung dalam alqur'an surah az-zukhruf: 32 :

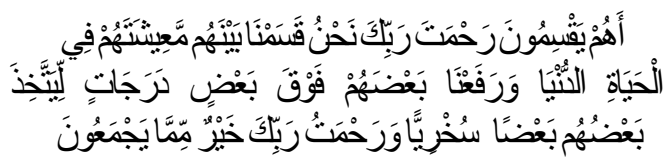

Artinya: Apakah mereka yang membagi-bagi rahmat Tuhanmu? Kami telah menentukan antara mereka penghidupan mereka dalam kehidupan dunia, dan kami telah meninggikan sebahagian mereka atas sebagian yang lain beberapa derajat, agar sebagian mereka dapat mempergunakan sebagian yang lain. Dan rahmat Tuhanmu lebih baik dari apa yang mereka kumpulkan.

\section{METODE PENELITIAN}

Jenis penelitian yang digunakan adalah jenis penelitian kuantitatif deskriptif. Adapun sumber data yang dipergunakan dalam penelitian ini adalah data primer dan data sekunder. Data primer yaitu data yang diperoleh langsung dari responden dengan melakukan penyebaran angket/kuesioner dan dokumentasi tentang pengaruh program keluarga harapan (PKH) terhadap kesejahteraan Keluarga Penerima Manfaat (KPM) di kecamatan tampan. Data Sekunder, yaitu data yang diperoleh dari pihak kedua yang dalam hal ini data dari 
Virna Museliza, Afrizal, Risma Elizal Pengaruh Program Keluarga Harapan (PKH) terhadap Kesejahteraan Keluarga Penerima Manfaat di Kecamatan Tampan Kota Pekanbaru

kantor Kecamatan tampan, dinas sosial dan unit pelaksana program keluarga harapan (UPPKH) kota pekanbaru. Metode Pengumpulan Data mengunakan angket atau kuesioner Kuesioner (angket) dan mengunakan teknik dokumentasi. Populasi dalam penelitian ini adalah keluarga penerima manfaat (KPM) program keluarga harapan (PKH) di kecamatan Tampan kota Pekanbaru. Sejumlah 1955 KPM PKH. Teknik pengambilan sampel pada penelitian ini menggunakanTeknik probability sampling dengan menggunakan teknik simple random sampling.

\section{HASIL DAN PEMBAHASAN}

\section{Variabel Program Keluarga Harapan} (X)

\section{1) Bantuan Sosial}

Bantuan sosial menurut PERMENSOS No 1 tahun 2018 adalah bantuan berupa uang, barang, dan jasa kepada keluarga dan/atau seseorang miskin, tidak mampu, dan/atau rentan. Dalam pelaksanaan program keluarga harapan $(\mathrm{PKH})$, para keluarga penerima manfaat (KPM) $\mathrm{PKH}$ salah satu haknya yaitu menerima bantuan sosial.

Dalam penelitian ini peneliti menggunakan indikator bantuan sosial yang diberikan oleh pemerintah hanya dalam berupa uang tidak dengan yang lain. Responden menjawab sangat setuju (32\%), setuju (59\%), kadang-kadang/ netral (5\%), tidak setuju (4\%), sangat tidak setuju $(0,5 \%)$. dapat disimpulkan bahwa tingkat persentase setuju menunjukkan angka terbesar, indikator ini merujuk ke pertanyaan bantuan sosial dan hampir semua jawaban dari responden setuju akan bantuan sosial yang diterima oleh KPM PKH baik dalam hal jumlah bantuan tunai dan waktu penerimaan bantuan sosial PKH di Kecamatan Tampan Kota Pekanbaru.

\section{2) Pendamping $\mathrm{PKH}$}

Pendamping $\mathrm{PKH}$ bertujuan yaitu memastikan anggota keluarga penerima manfaat PKH menerima hak dan kewajiban. para keluarga penerima manfaat (KPM)
PKH hak lainnya yaitu mendapatkan pendampingan PKH. Dalam penelitian ini peneliti menggunakan indikator pendampingan $\mathrm{PKH}$ sesuai dengan tugas pendamping $\mathrm{PKH}$.

Responden menjawab sangat setuju (32\%), setuju (71\% ), kadang-kadang/ netral (6\%), tidak setuju (1\%), sangat tidak setuju $(0,1 \%)$. dapat disimpulkan bahwa tingkat persentase setuju menunjukkan angka terbesar, indikator ini merujuk ke pertanyaan tentang pendampingan $\mathrm{PKH}$ yang berkaitan dengan tugas dan kewajiban para pendamping PKH kepada para KPM PKH di Kecamatan Tampan.

3) Mendapatkan Pelayanan Pendidikan Dan Kesehatan

Program keluarga harapan memfokuskan tujuannya pada pendidikan dan kesehatan terhadap KPM PKH, karena pendidikan dan kesehatan merupakan kebutuhan dasar yang perlu diperhatikan.

Responden menjawab sangat setuju (27\%), setuju (57\%), kadang-kadang/ netral ( $5 \%$ ), tidak setuju ( $11 \%$ ), sangat tidak setuju $(0 \%)$. dapat disimpulkan bahwa tingkat persentase setuju menunjukkan angka terbesar, indikator ini merujuk ke pertanyaan pelayanan kesehatan yang diterima oleh KPM PKH yang merupkan salah satu hak yang diterima oleh setiap KPM PKH.

4) Terdaftar Dan Mendapatkan Bantuan Komplementer

Bantuan komlementer menurut PERMENSOS No 1 tahun 2018 yaitu bantuan berupa uang, barang, dan jasa dibidang kesehatan, pendidikan, subsidi energi, ekonomi, perumahan dan pemenuhan kebutuhan dasar lainnya, sebagai pelengkap bantua sosial PKH. Atau dengan kata lain yaitu bantuan sosial lain yang diterima oleh KPM PKH.

Responden menjawab sangat setuju ( $26 \%)$, setuju (47\% ), kadang-kadang/ netral $(2 \%)$, tidak setuju $(20 \%)$, sangat tidak setuju (4\%) ). dapat disimpulkan bahwa tingkat persentase setuju 
Virna Museliza, Afrizal, Risma Elizal Pengaruh Program Keluarga Harapan (PKH) terhadap Kesejahteraan Keluarga Penerima Manfaat di Kecamatan Tampan Kota Pekanbaru

menunjukkan angka terbesar, indikator ini merujuk ke pertanyaan tentang bantuan komplementer atau bantuan lain yang diterima oleh KPM PKH untuk dapat memenuhi kebutuhan lain yang masih bisa dibilang merupakan kebutuhan pokok lainnya selain pangan.

\section{Variabel Kesejahteraan (Y)}

1) Kesehatan

Kesehatan merupakan salah satu indikator dari terwujudnya kesejahteraan, dalam penelitian ini, peneliti hanya mempertanyakan sudakahkah terpenuhinya jaminan kesehatan terhadap KPM PKH, karena kesehatan merupakan kebutuhan yang utama dalam kehidupan.

responden menjawab sangat setuju (28\%), setuju (59\%), kadang-kadang/ netral $(11 \%)$, tidak setuju ( $8 \%)$, sangat tidak setuju $(0.5 \%)$. dapat disimpulkan bahwa tingkat persentase setuju menunjukkan angka terbesar, indikator ini merujuk ke pertanyaan tentang bantuan yang diterima oleh KPM PKH berupa terpenuhinya kebutuhan akan kesehatan.

\section{2) Pendidikan}

Pendidikan merupakan indikator lain dari kesejahteraan, pendidikan kebutahan utama bagi setiap orang, karena salah satu upaya untuk meningkatkan kualitas sumber daya manusia (SDM) salah satunya dengan pendidikan.

Responden menjawab sangat setuju (24\%), setuju (55\%), kadang-kadang/ netral $(7 \%)$, tidak setuju $(10 \%)$, sangat tidak setuju (3\%). dapat disimpulkan bahwa tingkat persentase setuju menunjukkan angka terbesar, indikator ini merujuk ke pertanyaan tentang bantuan pendidikan yang diterima oleh anak-anak KPM PKH akan terpenuhinya kbutuha kan pendidikan dan tidak mengalami putus sekolah.

\section{3) Ketenagakerjaan}

Ketanagakerjaan merupakan indikator pentig lainnya dari kesejahteraan, karena permasalahan dibidang ketenagakerjaan salah satunya adalah pengangguran, oleh karena itu ketanagakerjaan merupakan tolak ukur dari kesejahteraan.

Responden menjawab sangat setuju $(28 \%)$, setuju (34\%), kadang-kadang/ netral (30\%), tidak setuju (25\%), sangat tidak setuju $(1 \%)$. dapat disimpulkan bahwa tingkat persentase setuju menunjukkan angka terbesar, indikator ini merujuk ke pertanyaan tentang ketenagakerjaan atau pekerjaan yang dimiliki oleh keluarga KPM PKH dan upah yang diterima mencupi kebutuhan atau tidak.

4) Pola konsumsi

Pola konsumsi rumah tangga merupakan salah satu indikator kesejahteraan rumah tangga/keluarga.

Responden menjawab sangat setuju (48\%), setuju (54\%), kadang-kadang/ netral ( $17 \%)$, tidak setuju ( $3 \%)$, sangat tidak setuju $(0,5 \%)$. dapat disimpulkan bahwa tingkat persentase setuju menunjukkan angka terbesar, indikator ini merujuk ke pertanyaan tentang pola konsumsi dalam pertanyaan ini peneliti membatasi pola konsumsi makanan yang baik hanya sebatas makanan yang layak dimakan oleh keluarga KPM PKH, serta tercukupinya makan sebanyak 3 kali sehari.

5) Perumahan

Perumahan merupakan kebutuhan primer yang dibutuhkan oleh manusia untuk keberlagsungan hidupnya.

Responden menjawab sangat setuju (24\%), setuju (64\%), kadang-kadang/ netral ( 5\%), tidak setuju ( $7 \%$ ), sangat tidak setuju ( $0 \%)$. dapat disimpulkan bahwa tingkat persentase setuju menunjukkan angka terbesar, indikator ini merujuk ke pertanyaan tentang perumahan atau tempat tinggal yang ditinggali oleh KPM PKH layak atau tidaknya serta terpenuinya akan kebutuhan listrik dan air bersih di rumah KPM PKH.

6) Kemiskinan

Kemiskinan merupakan aspek penting dalam indikator kejahteraan. Responden menjawab sangat setuju (18\%), setuju 
Virna Museliza, Afrizal, Risma Elizal Pengaruh Program Keluarga Harapan (PKH) terhadap Kesejahteraan Keluarga Penerima Manfaat di Kecamatan Tampan Kota Pekanbaru

(54\%), kadang-kadang/ netral (20\%), tidak setuju (7\%), sangat tidak setuju (1\%). dapat disimpulkan bahwa tingkat persentase setuju menunjukkan angka terbesar, indikator ini merujuk ke pertanyaan tentang terpenuhinya kebutuhan pokok KPM PKH serta bantuan yang diberikn oleh PKH dapat meringankan beban pengeluaran KPM PKH.

\section{UJI HIPOTESIS}

UJI REGRSI LINEAR SEDERHANA

Tabel 4. Hasil Uji Persamaan Regresi

\section{Coefficients $^{\mathrm{a}}$}

\begin{tabular}{|c|c|c|c|c|c|c|c|c|}
\hline \multirow{2}{*}{\multicolumn{2}{|c|}{ Model }} & \multicolumn{3}{|c|}{$\begin{array}{l}\text { Unstandardized } \\
\text { Coefficients }\end{array}$} & \multicolumn{2}{|c|}{$\begin{array}{l}\text { Standardized } \\
\text { Coefficients }\end{array}$} & & \\
\hline & & B & & Std. Error & Beta & & & \\
\hline 1 & (Constant) & & 9.888 & & & & 1.595 & .114 \\
\hline & $\begin{array}{l}\text { Proram keluarga } \\
\text { harapan }\end{array}$ & & .487 & & & .587 & 6.999 & .000 \\
\hline
\end{tabular}

a. Dependent Variable: kesejahtraan

Persamaan Regresi Sederhana

$\mathrm{Y}=\mathrm{a}+\mathrm{bx}$

Kesejahteraan $=9,888+0,487$ PKH Arti angka-angka dalam persamaan regresi diatas :

1. Nilai konstanta (a) sebesar 9,888 artinya adalah apabila PKH diasumsikan nol (0) maka kesejahteraan sebesar 9,888,

2. Nilai koefisien regresi variabel $\mathrm{PKH}$ sebesar 0,487 artinya adalah bahwa setiap meningkatnya $\mathrm{PKH}$ sebesar 1 satuan maka akan meningkat kesejahteraan sebesar 0,487 dan sebaliknya dengan asumsi variabel lain tetap.

\section{Pengujian Hipotesis Uji $T$ (Secara Parsial)}

Uji $t$ dasarnya untuk menunjukkan seberapa besar hubungan satu variabel independen secara individual dalam menerangkan variabel dependen. Uji $t$ merupakan prosedur yang digunakan untuk menguji kebenaran atau kesalahan hipotesis nol dan hasil sampel.

Tabel 5. Hasil Pengujian Hipotesisi Uji T

Coefficients $^{\mathrm{a}}$

\begin{tabular}{|c|c|c|c|c|c|c|c|}
\hline \multirow{2}{*}{\multicolumn{2}{|c|}{ Model }} & \multicolumn{2}{|c|}{$\begin{array}{l}\text { Unstandardized } \\
\text { Coefficients }\end{array}$} & \multicolumn{2}{|c|}{$\begin{array}{l}\text { Standardized } \\
\text { Coefficients }\end{array}$} & & \multirow[b]{2}{*}{ ig. } \\
\hline & & B & Std. Error & Beta & & & \\
\hline \multirow[t]{2}{*}{1} & (Constant) & 9.888 & 6.200 & & & 1.595 & .114 \\
\hline & $\begin{array}{l}\text { Proram keluarga } \\
\text { harapan }\end{array}$ & .487 & .070 & & .587 & 6.999 & .000 \\
\hline
\end{tabular}

a. Dependent Variable: kesejahtraan

\section{Sumber: Data Olahan Spss 21}

Secara individu (parsial) terhadap variabel terikatnya (kesejahteraan). Diketahui nilai t tabel pada taraf signifikasi
$5 \%$ (2-tailed) dengan persaman sebagai berikut:

$$
\begin{aligned}
\mathrm{T} \text { table } & =\mathrm{n}-\mathrm{k}-1: \mathrm{alpha} / 2 \\
& =95-1-1: 0.05 / 2
\end{aligned}
$$


Virna Museliza, Afrizal, Risma Elizal Pengaruh Program Keluarga Harapan (PKH) terhadap Kesejahteraan Keluarga Penerima Manfaat di Kecamatan Tampan Kota Pekanbaru

Keterangan

$$
\begin{aligned}
& =93: 0.025 \\
& =1,986
\end{aligned}
$$

$\mathrm{n}$ :jumlah sampel

$\mathrm{K}$ : jumlah variable bebas

L: konstan

Diketahui t hitung 6,200 > t table 1,986 atau sig $0.000<0.05$ untuk mengetahui apakah PKH berpengaruh terhadap kesejahteraan KPM PKH diliat dari kaidah keputusan .

Ho : Hipotesa yang menyatakan ketiadaan hubungan antara variabel yang sedang dioperasionalkan. Diduga "Tidak ada pengaruh Program Keluarga Harapan (PKH) terhadap kesejahteraan Keluarga Penerima Manfaat (KPM) di kecamatan Tampan"

Ha :Hipotesa yang menyatakan keberadaan hubungan diantara variabel yang sedang dioperasionalkan Diduga “ Ada pengaruh Program Keluarga Harapan (PKH) terhadap kesejahteraan Keluarga Penerima Manfaat (KPM) di kecamatan Tampan"
Berikut adalah kaidah pengambilan keputusan apakah PKH berpengaruh terhadap kesejanteraan KPM PKH atau tidak

a) Jika nilai $\mathrm{t}$ hitung $\geq \mathrm{t}$ tabel maka $\mathrm{H}_{\mathrm{O}}$ ditolak dan $\mathrm{H}_{\mathrm{a}}$ diterima, artinya signifikan

b) Jika Jika nilai t hitung $\leq \mathrm{t}$ tabel maka $\mathrm{H}_{\mathrm{a}}$ ditolak dan $\mathrm{H}_{\mathrm{o}}$ diterima, artinya tidak signifikan

Dengan demikian diketahui $\mathrm{t}$ hitung $6,200>\mathrm{t}$ table 1,986 atau sig $0.000<0.05$, Sehingga $\mathrm{H}_{\mathrm{O}}$ ditolak dan $\mathrm{H}_{\mathrm{a}}$ diterima, artinya adalah bahwaPKH berpengaruh signifikan terhadap kesejahteraan .Untuk menguji pengaruh PKH (x) terhadap kesejahteraan Keluarga Penerima Manfaat (KPM) di kecamatan Tampan (Y), digunakan uji statistic (uji t).

\section{Uji Koefisien Determinasi $\mathbf{R}^{\mathbf{2}}$}

Pengujian hipotesisi ini menggunakan koefisien determinasi (R2) bertujuan untuk mengetahui persentase variabel independen secara bersama-sam dapat menjelaskan variabel dependen. Untuk melihat ini koefisien determinasi, maka dapt dilihat dari tabel berikut ini:

Model Summary ${ }^{\mathrm{b}}$

\begin{tabular}{ccccc} 
Model & R & R Square & Adjusted R Square & Std. Error of the Estimate \\
\hline 1 & $.587^{\mathrm{a}}$ & .345 & .338 & 5.79571 \\
\hline
\end{tabular}

a. Predictors: (Constant), Proram keluarga harapan

b. Dependent Variable: kesejahtraan

Sumber: Data Olahan Spss 21

Hasil olahan statistic menunjukkan bahwa , uji koefisien korelasi $\left(\mathrm{R}^{2}\right)$ antara variabel $\mathrm{PKH}(\mathrm{X})$ dengan variable kesejahteraan (Y) didapat sebesar 0,345 sedengkan variable independen mampu menjelaskan variable dependen sebesar $34,5 \%$ sedangkan sisanya ( $100 \%-34,5 \%$ )
$=65,5 \%$ dijelaskan variabel lain tidak model ini (tidak diteliti).

Koefisien determinan memiliki fungsi untuk menjelaskan sejauh mana kemampuan variable independen (PKH) terhadap variable dependen (kesejahteraan). Hasil uii koefisien determinan tersebut memberikan makna 
Virna Museliza, Afrizal, Risma Elizal Pengaruh Program Keluarga Harapan (PKH) terhadap Kesejahteraan Keluarga Penerima Manfaat di Kecamatan Tampan Kota Pekanbaru

bahwa masih terdapat variable independent lain yang mempengaruhi yaitu sebesar 65,5 $\%$, uji koefisien determinan digunakan untuk mengukur seberapa besar persentase variasi variabel-variabel bebas $(\mathrm{PKH})$ pada model regresi linier dalam menjelaskan variasi variable terikat (kesejahteraan) nilai koefisien determinasi adalah antara nol (0) dan satu (1). Nilai R yang kecil berarti kemampuan variabel -variable independen dalam menjelaskan variable dependen amat terbatas. Nilai yang mendekati satu variable independen memberikan hamper semua informasi yang dibutuhkan untuk memprediksi variasi variable dependen.

Program Keluarga Harapan (PKH) yang telah diberikan sudah tergolong cukup baik, dalam penelitian regresi yang dilakukan, diketahui dari hasil uji t hitung 6,200 > t table 1,986 atau sig $0.000<0.05$. niali signifikansinya 0,05 . Dari hasil penelitian diperoleh nilai thitung $6,200>t_{\text {tabel }} 1,986$ maka Ho ditolak dan Ha diterima pada level signifikan 0,05 . Sehingga variabel $\mathrm{PKH}$ memiliki pengaruh terhadap kesejahteraan KPM PKH.

Semakin baik PKH (bantuan-bantuan $\mathrm{PKH})$ yang diberikan kepada KPM PKH maka akan semakin mambaik kehidupan para KPM PKH dan akan dapat membuat kehidupan KPM PKH menuju kehidupan yang sejahtera, begitupun sebaliknya, jika PKH (bantuan-bantuan PKH) yang diterima oleh KPM PKH tidak dapat memenuhi kebutuhan pokok kehidupannya ataupun tidak adanya peningktan bantuan $\mathrm{PKH}$ maka kesejahteraan KPM PKH tidak akan tercapai.

\section{PENUTUP}

Berdasarkan penelitian yang telah dilakukan di wilayah kecamatan tampan dan berasarkan analisis data maka dapat disimpulkan:

1. Berdasarkan uji regresi sederhana $\mathrm{Y}=$ $9.888+0,487 x$ Nilai konstanta (a) sebesar 9,888 artinya adalah apabila PKH diasumsikan nol (0) maka kesejateraan sebesar 9,888, Nilai koefisien regresi variabel PKH sebesar
0,487 artinya adalah bahwa setiap meningkatnya $\mathrm{PKH}$ sebesar 1 satuan maka akan meningkat kesejahteraan sebesar 0,487 dan sebaliknya dengan asumsi variabel lain tetap.

2. Berdasarkan uji $\mathrm{t}$ parsial diketahui $\mathrm{t}$ hitung $6,200>\mathrm{t}$ table 1,986 atau sig $0.000<0.05$ artinya adalah bahwa PKH berpengaruh signifikan terhadap kesejahteraan.

3. Berdasarkan uji koefisien determinasi (R2) diketahui uji koefisien korelasi (R) antara variabel PKH (X) dengan variable kesejahteraan (Y) di dapat sebesar 0.345 sedengkan variable independen mampu menjelaskan variable dependen sebesar $34,5 \%$.

4. Sehingga diperoleh hasil akhir bahwa Program Keluarga Harapan (PKH) berpengaruh terhadap kesejahteraan Keluarga Penerima Manfaat (KPM) di Kecamatan Tampan Kota Pekanbaru, hal ini dibutikkan dari hasil t hitung yang $\geq \mathrm{t}$ tabel sehingga.

\section{DAFTAR KEPUSTAKAAN}
Adi Isbandi Rukminto, 2013, Kesejahteraan Sosial, PT. Raja Grafindo, Jakarta.

Hadi prayitno Dan Lincolin Arsyad, 1987, Petani Desa Dan Kemiskinan, BPFE, Yogyakarta.

Huda Nurul, Dkk, 2015, Ekonomi Pembangunan Islam, Kencana, Jakarta.

Kementerian Sosial RI, 2011, Pedoman Umum Program Keluarga Harapan.

Kementrian Sosial RI, 2013, Pedoman Operasional Penyaluran Dana PKH .

Kementrian Sosial RI, 2013, Pedoman Operasional PKH Bagi Pemberi Pelayanan Kesehatan.

Kementrian Sosial RI, 2013, Pedoman Operasional PKH Bagi Pemberi Pelayanan Pendidikan. 
Virna Museliza, Afrizal, Risma Elizal Pengaruh Program Keluarga Harapan (PKH) terhadap Kesejahteraan Keluarga Penerima Manfaat di Kecamatan Tampan Kota Pekanbaru

Stalker Peter, 2008, Millenium Development Goals, Kita Suarakan Mdgs Demi Pencapaiannya Di Indonesia, Vol 1,1.

Sugiyono, 2013, Metode Penelitian Kuantitatif, Kualitatif Dan R\&D, Alpabeta, Bandung.

Sugiyono, Metode Penelitian Administrasi, 2008, Alpabeta, Bandung.

Suharto Edi, 2013 Kebijakan Sosial Sebagai Kebijakan Publik, Alfabeta, Bandung.

Suharto Edi, 2015, Analisa Kebijakan Publik, Afabeta Bandung

Sulaiman Andisajaya Syahputra \& Resnawati Resna, 2017, Program Keluarga Harapan (PKH): Antara Perlindungan Sosial Dan Pengentasan Kemiskinan, vol 4, 90 .

Wargadinata Wildana, 2011, Islam Dan Pengentas Kemiskinan, Press, Malang. 